\title{
Trajetórias transgêneras na educação de jovens, adultos e idosos: conquistas, horizontes e ameaças entre tempos, espaços e sujeitos escolares
}

\section{Transgender trajectories in youth, adult and elderly education: achievements, horizons, and threats among times, spaces, and school subjec} Trayectorias transgénero en la educación de jóvenes, adultos y ancianos: logros, horizontes y amenazas entre tiempos, espacios y temas escolares

Dayvi Santos ${ }^{1}$

Anna Luiza Martins de Oliveira ${ }^{1}$

DOI: http://dx.doi.org/10.20435/serie-estudos.v20i52.1398

\begin{abstract}
Resumo: Este artigo lança o olhar sobre narrativas transgêneras de estudantes que retornaram à escola através da Educação de Jovens, Adultos e Idosos (EJAI) da rede pública de Pernambuco. A permanência de jovens na escola é um problema histórico no Brasil, profundamente relacionado com fatores como a pobreza, o início precoce na vida laboral, o local da moradia (difícil acesso) e a falta de assistência à saúde. No caso das pessoas trans, esses aspectos se articulam à falta de reconhecimento, à ameaça constante de violência física e psicológica, à negação de acesso a espaços públicos e à precária rede de afetos e solidariedade. Essas trajetórias nos possibilitam pensar nos ambivalentes modos de existência que circulam e se cruzam no currículo, nos tortuosos e incompletos processos de criação de vidas forjados nas brechas da estrutura (cis-hetero) normativa e no efeito produtivo dos deslocamentos da política sexual no Brasil nas últimas duas décadas. O trabalho delineado busca apresentar-se como um recurso para demonstrar o sentido e o alcance real dos debates e das políticas de gênero e sexualidade no âmbito da educação, assim como para desmistificar as tentativas de reforçar estereótipos e projetar inimigos para buscar justificar a (re)produção de projetos históricos de dominação e exploração através do medo, do ódio e da violência.
\end{abstract}

Palavras-chave: trajetória escolar; transgeneridade; políticas de gênero e sexualidade; educação de jovens e adultos.

1 Universidade Federal de Pernambuco (UFPE). Recife, Pernambuco, Brasil. 
Abstract: This article looks at transgender narratives of students who have returned to the school through the Youth, Adult and Elderly Education Program (EJAI) of the Pernambuco public school. The permanence of young people in school is a historical problem in Brazil, deeply related to factors such as poverty, child labor, hard access to school and absence of health care. In the case of trans people, these aspects are linked to the lack of recognition, the constant threat of physical and psychological violence, the denial of access to public spaces and the precariousness of solidarity networks. These trajectories enable us to think about the ambivalent ways of life that circulate and intersect in the curriculum, in the tortuous and incomplete processes of creating lives forged between the holes of the (cis-hetero)normative structure and about the productive effects of sexual policy changes in Brazil over the last two decades. The outlined work seeks to present itself as a resource to demonstrate the deep meaning and importance of gender and sexuality studies and policies in education, as well as to demystify the attempts to reinforce stereotypes and justify the (re)production of historical projects of domination and exploitation through fear, hatred and violence.

Keywords: school trajectories; transgenderity; gender and sexuality policies; youth and adult education.

Resumen: Este artículo analiza narraciones transgénero de estudiantes que han regresado a la escuela a través de la Educación para Jóvenes, Adultos y Ancianos (EJAI) de la escuela pública en Pernambuco. La permanencia de los jóvenes en la escuela es un problema histórico en Brasil, profundamente relacionado con factores como la pobreza, el inicio temprano de la vida laboral, el lugar de residencia (difícil acceso) y la falta de atención médica. En el caso de las personas trans, estos aspectos están relacionados con la falta de reconocimiento, la amenaza constante de violencia física y psicológica, la negación del acceso a espacios públicos y la precaria red de afecto y solidaridad. Estas trayectorias nos permiten pensar en los modos ambivalentes de existencia que circulan e intersectan en el plan de estudios, en los procesos tortuosos e incompletos de creación de vida forjados en las infracciones de la estructura (cis-hetero)normativa y en el efecto productivo de los cambios en la política sexual en Brasil en las últimas dos décadas. El trabajo resumido busca presentarse como un recurso para demostrar el significado y el alcance real de los debates y de las políticas de género y sexualidad en la educación, así como para desmitificar los intentos de reforzar los estereotipos y proyectar enemigos para tratar de justificar la (re)producción de proyectos históricos de dominación y explotación a través del miedo, del odio y de la violencia.

Palabras clave: carrera escolar; transgénero; políticas de género y sexualidad; educación de jóvenes y adultos.

\section{INTRODUÇÃO}

Transgredir, traficar signos e transitar entre os gêneros estabelecidos pela realidade cisnormativa hegemônica implica em assumir um movimento de ruptura com uma identidade "predestinada". Antes mesmo de nascer, o corpo já se encontra inscrito num campo discursivo que estabelece vínculo obrigatório entre genital e gênero, criando parâmetros que demarcam a rotina do sujeito (LANZ, 2016), sua imagem, seus desejos, seus limites e reduzem a complexidade 
humana à questão anatômica. A ênfase no traço biológico estimula projeções sociais, impõe condutas. A unidade tão reclamada, entretanto, mostra-se falha e insustentável quando a corporeidade renega tal reconhecimento. Na tentativa de fixar sentidos, a reiteração normativa coloca à margem quem dela faz pouco caso e escárnio, mas não consegue excluir plenamente. Afinal, no jogo relacional da significação, o abjeto é seu exterior constitutivo, sua condição de possibilidade e, ao mesmo tempo, a constatação de que não há estruturas sociais universais (LACLAU; MOUFFE, 2015). A identidade é sempre construída e ameaçada por alguma coisa externa a ela.

A construção discursiva da transgeneridade é marcada por um histórico processo de patologização identitária (LEITE JÚNIOR, 2008) que autoriza quem dita as normas a realizar, com as próprias mãos, uma "assepsia social" legitimada pelos compêndios médicos: distúrbio, anormalidade, desvio, disforia, transtorno. Quanto trabalho semântico! O sexo, já nos dizia Butler (2000), é um ideal regulatório forçosamente materializado e reiterado a serviço de predileções políticas e sociais de um tempo. Instituições imbricadas pelo binarismo de gênero assumem o papel de guardiãs desta ordem social na qual a heterossexualidade e a cisgeneridade tornam-se loci privilegiados por dispositivos que as naturalizam.

Em contrapartida, quem não obedece a esse padrão é corpo sem lugar, sem valor e, por não ter existência legítima, torna-se passível a todo tipo de violação. A repressão ao "desvio" deve ser pública e implacável, afinal, está em jogo a salvaguarda de um projeto social. A engenharia de produção de "corpos normais" encontra no espaço-tempo do currículo um terreno privilegiado de disseminação. Reiterar incansavelmente as normas se faz necessário, considerando a instabilidade de materialização desses corpos e o risco de não conformidade.

Tanto na sua superfície, quanto no seu interior, o corpo é um fenômeno social: ele está exposto aos outros, é vulnerável por definição. Sua mera sobrevivência depende de condições e instituições sociais, o que significa que, para "ser" no sentido de sobreviver, o corpo tem que contar com o que está fora dele [...] Ele não é, contudo, uma mera superfície na qual são inscritos significados sociais, mas sim o que sofre, usufrui e responde à exterioridade do mundo, uma exterioridade que define sua disposição, sua passividade e atividade. (BUTLER, 2018, p. 57-8).

A hostil exterioridade do mundo às pessoas transgêneras alenta reações e, nas brechas da estrutura regulatória, emergem vidas precárias. Na fragilidade 
existencial, vagueia-se por lugares que parecem não terem sido feito para elas, com seus armários trancafiados e homens em catarse expurgando fetiches no reinado de Momo. A escola, nesse contexto, aparece como um dos locais mais inóspitos para permanência dos que transitam entre gêneros.

Em pesquisa nacional sobre o ambiente educacional (ASSOCIAÇÃO BRASILEIRA DE LÉSBICAS, GAYS, BISSEXUAIS, TRAVESTIS E TRANSEXUAIS [AGBLT], 2016), constatou-se que $60 \%$ dos estudantes LGBTs brasileiros se sentem inseguros na escola em decorrência de sua sexualidade, $27 \%$ já foram agredidos fisicamente e $73 \%$ verbalmente. Sobre as medidas tomadas pela instituição de ensino, 54\% alegaram omissão por parte da gestão. Essa "sinergia de vulnerabilidades" (PARKER; CAMARGO JÚNIOR, 2000) ampara-se na fragilidade constitutiva de ações voltadas ao enfrentamento das discriminações, assim como de políticas públicas destinadas às necessidades básicas desse segmento, como acesso aos estudos, à profissionalização e a serviços básicos em saúde, habitação e segurança. A conjunção desses fatores favorece o afastamento do sistema de ensino e a desistência das atividades escolares, fenômeno tecnicamente denominado de "evasão" escolar. Estima-se que cerca de $82 \%$ das travestis e transexuais brasileiras abandonaram a escola pelo menos uma vez ao longo da vida (HANNA; CUNHA, s.d.), sendo comum a não conclusão do ensino básico, o que gera uma série de desdobramentos no acesso ao trabalho e na qualidade de vida.

Tratar com naturalidade a interrupção da trajetória escolar de estudantes transgêneres ${ }^{2}$ representa o descompromisso institucional com o acesso e a permanência estudantil enquanto princípio norteador da política educacional. Os olhares de repúdio, ofensas verbais, agressões físicas e o desrespeito institucional à identidade dessas pessoas relatados em diversos estudos (JUNQUEIRA, 2009; CRUZ, 2011; AVILA, 2014; FRANCO; CICILLINI, 2015;) demonstram que a própria terminologia "evasão" é inadequada: trata-se de expulsão (BENTO, 2011) que retroalimenta a engrenagem de vivências precárias.

A existência de uma vida, diz-nos Butler (2018), só é reconhecida quando passível de luto e garantida por uma série de direitos providos por diferentes instituições - Poder Judiciário, saúde, educação etc. A quem pertence o status de

\footnotetext{
2 Segundo Jaqueline Gomes de Jesus (2012), o termo transgênero é usado para designar uma pluralidade de sujeitos que não se identifica, em graus diferentes, com comportamentos e/ou papéis esperados do gênero que Ihes foi designado socialmente.
} 
"humano"? Quais corpos podem ser chorados? Quais mortes são sentidas? Quais violências são percebidas? É por meio da capacidade de comoção que as vidas são classificadas como "merecedoras de luto e de proteção", as que não passam por esse crivo estão apenas vivas no campo do precário. Onde se encaixam as vivências transgêneras?

Em 2018, foram registrados e contabilizados 163 assassinatos de pessoas trans no Brasil (BENEVIDES; NOGUEIRA, 2019). Pernambuco ocupa a oitava posição no ranking nacional e a terceira em nível regional. Com um total de sete mortes, entre os casos conhecidos, estão: Evelim Ferrari, A. S. Silvério, Renata, Shirley, Raquel, Bia Rocha e Heimilly. De acordo com a Associação Nacional de Travestis e Transexuais (ANTRA, 2018), 90\% da população de travestis e mulheres transexuais utiliza a prostituição como possibilidade de subsistência em virtude da pouca aceitação no mercado formal de trabalho, da deficiência na qualificação profissional e da baixa escolaridade, o que aumenta sua vulnerabilidade.

Mas, se a instituição educacional tem desempenhado "bravamente" o papel de salvaguarda da cisnormatividade ao naturalizar determinadas formas de ser e existir em detrimento de outras, ainda assim não tem conseguido barrar totalmente a presença de alguns corpos dissonantes, embebecidos da coragem de Virgínia Guitzel $^{3}$, que renegam a rendição, desafiam os senhores e sonham com um banheiro para chamar de seu, com o reconhecimento do nome social e/ ou com o retorno à escola.

Este artigo lança o olhar, portanto, sobre narrativas transgêneras de estudantes que retornaram à escola através da Educação de Jovens, Adultos e Idosos (EJAI) da rede pública de Pernambuco. Pessoas que, após experimentarem trajetórias de exclusão e expulsão do sistema escolar, decidiram investir novamente no projeto de escolarização - apesar dos traumas, cicatrizes, dores, custos e riscos já bem conhecidos - como caminho de construção subjetiva pessoal e/ou coletiva. Inicialmente, apresentamos de forma panorâmica e dentro dos limites possíveis desse texto memórias das trajetórias escolares dessas pessoas, destacando, especialmente, alguns dos fatores que levaram à expulsão e ainda tensionam sua presença no contexto escolar. Em seguida, elencamos alguns dos aspectos

3 Virgínia Guitzel é uma travesti, poeta e militante feminista que trabalha como agente de saúde pública com usuários em abandono de tratamento para HIV/aids. 
e processos que têm estimulado a reaproximação desses grupos do caminho da escolarização, destacando principalmente a política do nome social.

Num tempo de acirrada disputa em torno das políticas educacionais de gênero e sexualidade (OLIVEIRA; OLIVEIRA, 2019; 2018) e de propagação de pânicos morais (RUBIN, 1993; MISKOLCI, 2007) sobre os perigos de uma falaciosa "ideologia de gênero" que visa à "destruição da família", à "legalização da pedofilia", à "naturalização da zoofilia" e às "liberações sexuais na tenra idade", o Ministério Público (MPPE), após acompanhar um caso de transfobia na rede de ensino, emitiu recomendação à Secretaria de Educação de Pernambuco (SEE) para que garantisse o debate sobre gênero e sexualidade na escola. No conjunto de ações atualmente desenvolvidas pela SEE, com foco nessa recomendação, destacam-se: i) o Prêmio Naíde Teodósio de Estudos de Gênero; ii) o apoio aos Núcleos de Estudos de Gênero e Enfrentamento da Violência contra a Mulher; iii) a Andanças - Mostra de Cinema de Gênero e Diversidade; iv) a inserção do tema integrador "relações de gênero" no currículo do ensino fundamental; v) a política de reconhecimento e uso do nome social. A política de uso do nome social foi implementada pela SEE a partir do ano letivo de 2017 e, desde então, foram registrados 325 pedidos entre as/os estudantes. A maioria está matriculada na EJAl.

\section{MEMÓRIAS DE TENSÕES, CONFLITOS E EXPULSÕES ESCOLARES}

A discussão que realizamos neste artigo se baseia em dados parciais da pesquisa realizada por Santos (2019) com doze pessoas que transitam entre gêneros ${ }^{4}$ e que estão ou estiveram matriculadas/os na EJAI, em escolas públicas pernambucanas, entre os anos de 2017 e 2019. A seleção das/os participantes foi referenciada nos dados disponibilizados pela Gerência de Políticas Educacionais em Educação Inclusiva, Direitos Humanos e Cidadania (GEIDH) da Secretaria de Educação de Pernambuco, a partir da política de uso do nome social e dos registros de ocorrência escolar envolvendo estudantes transgêneros/as. Durante a pesquisa de campo, foram percorridos dez municípios e quatro mesorregiões ${ }^{5}$ do Estado.

4 Que se identificaram como mulheres trans, homens trans, travestis e/ou outras identidades não binárias.

5 Entre os anos de 1989 e 2017, o IBGE dividiu geograficamente o Estado de Pernambuco em cinco mesorregiões (Sertão Pernambucano, São Francisco Pernambucano, Agreste Pernambucano, Mata Pernambucana e Mesorregião Metropolitana do Recife), que abrangiam 185 municípios. 
Geralmente, um espaço reservado na instituição possibilitava o ambiente necessário para o aprofundamento do encontro. Biblioteca, laboratório de informática, direção escolar ou sala de educador de apoio serviram como abrigo para as entrevistas narrativas, cuja "ideia básica é reconstruir acontecimentos sociais a partir da perspectiva dos informantes, tão diretamente quanto possível" (JOVCHELOVITCH; BAUER, 2010, p. 93). Porém, assim como nas memórias, o passado não "retorna em si" nas narrativas. Reconstrói-se discursivamente de forma não linear, em que o tempo de cada um também é o tempo coletivo, assim como a história de cada pessoa é a história de várias vozes, atravessada por uma conjugação de sentidos.

Ao revisitar suas vivências, as/os participantes remexeram, bagunçaram e reinventaram significados. Recorreram a lembranças como quem tece fios de histórias aparentemente perdidos no e com o tempo, deslocando e problematizando sentidos em diferentes direções (HALL, 2003). Se o currículo escolar tradicionalmente enfatiza as vivências de grupos hegemônicos, deslocar o olhar para estas experiências trouxe à tona as fissuras presentes neste discurso que pretensiosamente busca ser universal.

Cada participante teve a oportunidade de escolher um nome fictício a partir de suas referências e preferências. Não foi tarefa fácil, manifestaram o desejo de terem seu "nome verdadeiro" registrado nessas páginas, por considerar peça-chave na reafirmação de uma existência negada em casa, no trabalho, na rua e na escola. Sem desfazer desta luta diária, em tempos de disseminação do ódio, preservar a identidade de pessoas que cotidianamente já possuem um alvo estampado em seus corpos era "mal necessário". Sigamos! A mão do tempo revela onde fica a memória.

Na Tabela 1, listamos os nomes das/os participantes, suas idades, a região do Estado onde estudam e como se identificam em relação ao gênero. Apenas um (Heitor) encontra-se no ensino fundamental (IV fase da EJAI), as/os demais cursam diferentes módulos do ensino médio. 
Tabela 1-Caracterização das/os participantes da pesquisa quanto à idade, etapa na EJAI, região do Estado onde estuda e identidade de gênero

\begin{tabular}{|c|c|c|c|c|}
\hline Nome & Idade & Etapa na EJAI & Região & Id. de Gênero \\
\hline Benedita & 24 & 3o módulo & Sertão & Travesti \\
\hline Celeste & 25 & 3o módulo & Mata Centro & Mulher \\
\hline Davi & 22 & 3o módulo & Mata Norte & Homem trans \\
\hline Elizabeth & 25 & 1ํo módulo & Mata Centro & Travesti \\
\hline Fernando & 20 & 2o módulo & Mata Sul & Homem trans \\
\hline Felipe & 19 & 2o módulo & Recife & Homem trans \\
\hline Heitor & 16 & 4a fase & Recife & Homem trans \\
\hline Janaina & 24 & 2o módulo & Recife & Mulher trans \\
\hline Maria & 19 & 2ำ módulo & Sertão & Mulher trans \\
\hline Renato & 18 & 2o módulo & Recife & Homem trans \\
\hline Rosa & 42 & 2ำ módulo & Recife & Travesti \\
\hline Valentina Gabrielly Knowles & 23 & 3o módulo & Agreste & Mulher trans \\
\hline
\end{tabular}

Fonte: Santos (2019).

O regresso de uma pessoa trans à escola traz consigo sonhos, expectativas, marcas físicas e psíquicas dos obstáculos vividos no passado e no presente. Os trajetos percorridos diariamente para chegar ao espaço educacional por si já dizem muito sobre suas relações urbanas cotidianas. A cidade vive, revive e sobrevive das movimentações e afetações entre os sujeitos. Cidade-corpo, construída do atravessamento do nosso corpo pelo corpo da cidade, o qual se molda por instituições, práticas e (des)encontros em que a carne é matéria que, ao se chocar com as interferências do espaço, forja subjetividades, conferindo memórias e significados (HISSA, NOGUEIRA, 2013, p. 61). Nos encontros, confrontações, diferenças e reconhecimentos, o sujeito vai sendo (re)significado e constituído.

Benedita, 24 anos, performer, sertaneja, negra, travesti e bissexual, cursando o 3 o módulo da EJAl (ensino médio), numa escola situada no sertão do Moxotó-Ipanema, diariamente se depara com o desafio de talhar sua existência na superfície sólida e resistente de estruturas sociais (cis)generificadas: Eu não me sinto acolhida pela cidade. Antes eu era mais acolhida, as pessoas me convidavam, sabe? Depois que eu assumi minha identidade de gênero essas pessoas se afastaram. A arte é seu antídoto e veneno. O reconhecimento nessa área veio através da escola ao ganhar uma gaita como prêmio por ter produzido a melhor montagem teatral sobre o "meio ambiente". 
Começou a sobreviver de arte naquele ambiente hostil. Esquetes sobre drogas, gincana, abertura dos jogos internos. Para além das paredes da instituição de ensino, seu ofício ecoou pelo município. Nos dias que antecedem a sua intervenção artística na cidade, convida meninas transexuais e travestis para prestigiar e refletir sobre a performance. Em uma das apresentações recentes, abordou o cotidiano das "bombadeiras" e suas relações com as travestis de Arcoverde que migram para Minas Gerais e São Paulo agenciadas por cafetinas. Benedita recebe críticas por parte da classe artística local, que lhe cobra um trabalho mais conceitual, esquecendo-se de que estar viva fazendo aquilo já é um conceito. Vida que não se findou por um triz: Eu estava na praça conversando com os amigos e um boy que eu não sei de onde é, me deu um murro no pescoço... Na delegacia o pessoal queria que eu identificasse quem era a pessoa que me agrediu e eu não tinha como saber, porque eu não o conhecia.

O trajeto para escola é percorrido a pé, considerando a proximidade com sua casa, mas nem sempre a ida à escola é tranquila. Tem piadas, os garis tiram onda quando eu passo na rua. Garis, homens jogando futebol, adolescentes fardados, bêbados eufóricos, vendedores ambulantes. Os personagens variam, mas as agressões verbais são as mesmas de acordo com relatos de vários/as estudantes. A fragilidade de políticas públicas voltadas a travestis e transexuais com vista à garantia da integridade de seus corpos encontra-se alinhada à perspectiva de uma cidade que salvaguarda a cisnormatividade. Se os corpos cisgêneros transitam livremente e acessam diversos serviços, aos que transgridem a norma resta o medo de ocupar espaços públicos e o descrédito no Estado como responsável por assegurar a "ordem social".

Renato, 18 anos, homem trans, bissexual, estudante da região metropolitana do Recife, onde cursa o 2 o módulo do ensino médio, cita outro exemplo de como a violência urbana reverbera em seus corpos: Nunca fui de ficar muito na rua, sou muito calmo, fechado. Sofri muita agressão na rua, assédio. Sofri tentativa de estupro por um amigo do meu pai. Eu fui buscar meu irmão na escola e ele me perseguiu. Meu pai foi tirar satisfação, mas não me deixou fazer a queixa.

6 Bombadeiras são travestis que aplicam cladestinamente silicone em outras travestis e mulheres trans. Na maioria das vezes, esse silicone é do tipo industrial, cujo uso é vedado a seres humanos, mas que para boa parte dessas pessoas é o único ou o mais acessível meio de "feminilizar" o corpo. 
O ciclo de experiências negativas vivenciadas na prostituição levou Janaína, mulher trans, 24 anos, cursando o 2 o módulo do ensino médio na região metropolitana do Recife, a ter aversão ao espaço público: Não sou de sair muito não. Não confio em homem nenhum. Recordou, com amargura, de quando tinha seus quinze anos e foi casada com uma pessoa que lhe impedia de frequentar a escola. Atualmente, seu lazer se resume a festividades junto a amigas que conheceu durante o trabalho nas ruas, confirmando resultados de outros estudos (BENEDETTI, 2005; PELÚCIO, 2009) de que, para além do retorno financeiro, a prostituição proporciona a mulheres trans e travestis a construção de redes de afeto que raramente encontram em outros locais.

Residente em área rural, Valentina Gabrielly Knowles ${ }^{7}, 23$ anos, mulher trans, matriculada no 3 o módulo de uma escola do agreste pernambucano, faz uso de transporte escolar. O caminho é longe, escuro, quando eu chego em casa é quase onze horas da noite. Por vezes, pensou em desistir dos estudos pelos comentários e risadas que lhe acompanham no ônibus. Chegou a desabar no choro, prometendo não retornar mais àquele lugar. No outro dia estava lá, à espera do coletivo e de mais uma batalha.

Se os caminhos para se chegar à escola são conturbados, as memórias sobre a instituição de ensino guardam aromas e sabores particulares. Poucos segundos foram necessários para que as/os estudantes lembrassem de experiências significativas. Quando Maria (19 anos, mulher trans do sertão de Pernambuco) e Elizabeth (25 anos, travesti, residente na Mata Centro de Pernambuco) sentem cheiro de comida, lembram da escola que muitas vezes saciou sua fome, situação também vivenciada por Benedita: Cheiro da cozinha, da comida, não tem como não lembrar. Várias vezes eu saía de casa sem almoçar por não ter comida mesmo. Rosa, 42 anos, travesti, residente no Recife, lembrou-se de bananas: Tinha uma cozinheira que era muito amorosa e ela sempre oferecia uma bananinha para mim e me dava um abraço. Nunca nada é cem por cento ruim, né, amiga? A recordação do carinho e cuidado demonstrado pela servente à estudante é raridade entre as lembranças estudantis.

Para Heitor, 16 anos, homem trans, matriculado na 4a fase do ensino fundamental no Recife, a escola tem cheiro da erva. Me viram fumando, pediram

\footnotetext{
7 A escolha do seu nome deriva da homenagem a três pessoas pelas quais nutre profunda admiração: Valentina refere-se à drag queen que participou da 9ạ temporada de RuPaul's Drag Race, Gabrielly era o nome da sua falecida bisavô e Knowles é o sobrenome de Beyoncé.
} 
para chamar minha mãe e eu passei um mês sem entrar. Foi bem complicado. Eu uso, frequentemente, para poder aguentar as pessoas daqui. Para Felipe, 20 anos, homem trans da Mata Sul, a memória é daquelas máquinas de antigamente que botavam o papel, o álcool. Lembro daquele cheiro. Vinculada à recordação do mimeógrafo, ele ressalta a visibilidade estudantil, considerando que a professora por diversas vezes the escolhia como responsável pela reprodução do material pedagógico, sendo esta também a lembrança de Fernando (19 anos, homem trans, do Recife), inserido na mesma lógica de "protagonismo".

O odor do banheiro masculino foi rememorado por Valentina, acompanhado de vários relatos de violência sofrida neste "não lugar". Vítima de agressão física por parte de colegas no sanitário escolar, ao longo da vida teve diversos problemas urinários por não usar o banheiro em espaços públicos. Como discutido em vários estudos (BROWNE, 2004; MUNT, 1998; HALBERSTAM, 1998), o banheiro de instituições públicas consiste numa estrutura extremamente difícil de ser habitada pelas pessoas trans. Entre os símbolos e arranjos arquitetônicos constituintes da gramática escolar, é um dos mais produtivos de sentido sobre o sujeito, "ele não apenas nos diz onde ir, ele nos diz o que somos, a que lugares pertencemos e a que lugares não pertencemos" (RASMUSSEN, 2009, p. 439). Sentido reforçado por Fernando, no dia de seu aniversário, ao escolher o banheiro dos professores para tentar o suicídio.

A tirania de gênero começa ainda na educação infantil e participa ativamente do processo de (não)reconhecimento do sujeito como pessoa. Quanto mais próximo dos regimes de verdade sobre gênero, mais inteligível é o sujeito. Porém, como insiste Butler (2000), ao mesmo tempo em que esse regime de verdade controla, nomea e legitima certas vidas em detrimento de outras, os sentidos não estão dados, as brechas estruturais possibilitam ressignificações, experimentações dissidentes tensionam e modificam os azados termos da legitimação simbólica. São momentos efêmeros como os de Celeste, que, ao lembrar do banheiro escolar, diverge da maioria citando experiências sexuais agradáveis com o namorado, ou da própria Valentina, que ao retornar à escola, agora na EJAl, é surpreendida pelo acolhimento do diretor: Ele me deu a chave do banheiro feminino e eu disse: o senhor me deu a chave errada. Ai ele disse: a partir de agora é esse banheiro que você vai usar. Assim, outros significados vão sendo tecidos à força e sangue "com aquilo que se tem na mão e no corpo, no quadril e nos pés (RANNIERY, 2016, p. 103). 
Qualquer análise sobre os processos de precarização das vidas transgêneras sem lançar um olhar sobre o recorte de classe corre o risco de produzir reflexões superficiais. Benedita já trabalhou em lojas de festas e vendendo bingo. Participou de grupo de teatro e dança em que recebia (algumas vezes) cachês por apresentação. A necessidade financeira foi um dos motivos que a fez sair da escola. Às vezes eu não estava na escola porque eu precisava de dinheiro, sabe? Eu precisava trabalhar para ter o dinheiro. Inclusive agora, para terminar, tem sido muito difícil. Atualmente, Benedita reconhece a escola enquanto lugar de superação, mas nem sempre foi assim. A primeira "evasão" ocorreu na 5a série: a mãe a levava à força para escola e, em seguida, ela pulava o muro. Eu estava sendo agressiva com todo mundo para me defender. Não tinha conversa na escola, não tinha diálogo. Retornou aos 16 anos, desta vez matriculada na EJAl. O público era mais velho, mais maduro, o que the fez acreditar que as coisas poderiam ser diferentes, mas se enganou. Um menino lá da sala perguntou a um professor, olhando para mim, se ele iria preso caso batesse muito numa pessoa até tirar sangue. Foi uma das coisas que quase me fez desistir, porque foi uma ameaça.

Durante três meses, Davi vendeu água no litoral de São Paulo. Na época, já não estava em sala de aula. O afastamento se deu por uma confluência de três fatores: o desrespeito entre os colegas, a dificuldade em lidar com as transformações corporais e a morte de uma pessoa da família. Retornou à instituição de ensino no intuito de se formar e ingressar numa faculdade, motivado pelo sistema de cotas. Concluir o ensino básico também lhe daria melhores condições para competir no mercado de trabalho, por isso considera a escola como segunda casa, onde se aprende tudo. E onde se é capaz de ensinar também. Por diversas vezes, corrigiu uma professora que insistia em Ihe tratar no feminino. Quando a secretaria imprimia uma listagem contendo seu nome civil, prontamente arrancava o papel e dava as instruções necessárias para que o erro fosse corrigido.

Por que você não vai trabalhar no sinal vendendo pipoca e água? Foi assim que Heitor foi interrogado por um amigo da irmã que visitava sua casa. Inscrito no Programa Jovem Aprendiz, nunca foi chamado para participar de qualquer processo seletivo. Caso fosse necessário trabalhar no horário de aula, afirma que trocaria de turno sem pensar duas vezes. A ânsia pela empregabilidade deriva, em grande parte, pela possibilidade de superar os conflitos familiares. Aos sete anos de idade, tentou o suicídio pela primeira vez: se jogou na frente de um car- 
ro. Algum tempo depois, cortou os pulsos. Começou a faltar as aulas. Não queria encontrar pessoas, não queria falar, não queria ouvir ninguém. Reprovou. Duas professoras Ihe prestaram auxílio. Atualmente, pretende se dedicar aos estudos e ingressar na carreira de Jornalismo.

Janaína trabalhava manhã, tarde e noite. Na prostituição era assim, até bêbada eu ia. Inicialmente, revezava-se entre a avenida e a sala de aula. Insultos, pedras, violências cotidianas. O corpo não suportou tamanho desgaste. Parou de estudar. Muitos homens diziam que eu era bonita, inteligente. A vida se tornava cada vez pior e me dei conta de que era hora de parar e de tomar outro rumo. Decidiu voltar para sala de aula. Seguiu o conselho de uma amiga travesti: a gente trans tem que fazer faculdade para ser alguma coisa na vida. Pretende cursar Enfermagem, sugestão de um cliente que era cirurgião. Hoje, além de estudar, vende jogo do bicho.

Maria trabalha há quatro meses na Secretaria de Saúde do município, oportunidade única que o prefeito da cidade me deu. Pensou que não seria bem recebida por ser mulher trans, mas sente-se acolhida no espaço. Além de trabalhar na limpeza, dá aula de dança no Centro de Atenção Psicossocial (CAPS). A carga de trabalho no CAPS juntamente dos ensaios dos grupos de dança interfere no seu desempenho escolar. Constantemente falta aulas e deixa de entregar trabalhos.

Rosa também enfrentou uma série de dificuldades ao tentar conciliar trabalho e estudo. Eu passei vinte e seis anos afastada do âmbito escolar. Primeiro porque tinha trabalho, curso de cabeleireira, eu não conseguia dar conta. Depois, quando eu comecei a minha transição, eu via que a escola não era um lugar para mim. A aceitação era péssima! Com a crise financeira, retornou à escola. Eu quero uma outra profissão. Já sabia da política do nome social e quando eu cheguei aqui fui acolhidíssima. Hoje eu faço parte de uma escola em que todas as pessoas trans devem estudar. Seu sonho é cursar Serviço Social e trabalhar com políticas públicas destinadas a travestis e mulheres trans.

Há um consenso entre as/os participantes do estudo em relação à educação enquanto plataforma para outras vivências, o processo de escolarização é visto como possibilidade de reconhecimento social, de conquistas materiais e de realização profissional. As memórias escolares, portanto, não são alheias ao contexto social mais amplo. A permanência de crianças e, principalmente, de jovens na escola é um problema histórico no Brasil, profundamente relacionado com fatores como a pobreza, o início precoce na vida laboral, o local da moradia (difícil acesso) 
e a falta de assistência à saúde. Estima-se que, de cada 100 estudantes que ingressam no ensino fundamental, apenas 36 concluem o ensino médio (NERI, 2009). No caso das pessoas trans, esses aspectos se somam, articulam-se e se sobrepõem à falta de reconhecimento, à ameaça constante de violência física e psicológica, à negação de acesso a espaços públicos e à precária rede de afetos e solidariedade.

Na última década, entretanto, percebe-se uma reaproximação desse público com a escola, especialmente a partir da implementação de leis, políticas públicas e ações voltadas para a população LGBT, entre as quais se destacam: o Brasil sem Homofobia (2004); as Conferências Nacionais de Políticas Públicas e Direitos Humanos de LGBT (2008, 2011, 2016); o Programa de Combate à Intimidação Sistemática (Lei 13.185/2015); os editais do MEC de fomento à formação docente em gênero, sexualidade e enfrentamento da LGBTfobia na escola (OLIVEIRA; OLIVEIRA, 2018) e o Decreto 8.727/2016, que permite o uso do nome social e o reconhecimento da identidade de gênero de pessoas travestis e transexuais no âmbito da administração pública federal direta, autárquica e em todos os órgãos públicos.

\section{O RETORNO À ESCOLARIZAÇÃO DE PESSOAS TRANS: SOBRE NOMES, ESPAÇOS E HORIZONTES}

Desde $2008^{8}$, várias legislações municipais, estaduais e nacionais têm pautado a garantia ao uso do nome social de pessoas trans nos estabelecimentos de ensino brasileiros. Do ponto de vista jurídico, o nome faz parte dos direitos personalíssimos, categoria que também engloba o direito à vida, ao corpo, à integridade física e moral, à intimidade e à liberdade. É por meio dele que se referencia a existência de uma pessoa perante o Estado e as instituições (PRÓCHNO; ROCHA, 2011). O nome acompanha o sujeito desde antes de seu nascimento e, em geral, permanece até depois de sua morte, produzindo sobre ele sentidos - de posse, de pertença a determinada família, religião, território, classe social, de relações de gênero e sexualidade. A categoria nome, portanto, além de acionar práticas de significação de subjetividades, prevê uma certa estabilidade da identidade civil, que é tensionada pelos que transitam entre gêneros.

\footnotetext{
${ }^{8}$ A Secretaria de Educação do Estado do Pará, por meio da Portaria n. 16/2008-GS, foi a primeira a implantar a política do nome social no país. Na época, sua principal motivação foram os altos índices de violência e homicídio da população LGBT na região.
} 
A Secretaria de Educação de Pernambuco implementou a política de uso do nome social a partir do ano letivo de 2017, atendendo a uma indicação do Ministério Público, após o acompanhamento de um caso de transfobia numa unidade de ensino situada no Recife. Em 2018, o lançamento de um requerimento específico e a possibilidade de solicitar a garantia desse direito em qualquer época do ano ampliaram o número de usuários/as. A política também se fortaleceu através de campanhas nas redes sociais e da criação de espaços formativos destinados ao corpo docente, gestão escolar e setores administrativos. Através da Tabela 2, podemos observar, portanto, que a quantidade de estudantes requerentes praticamente duplicou em três anos.

Tabela 2 - Quantidade de estudantes, por gênero, que solicitaram o uso do nome social na rede de ensino do Estado de Pernambuco entre os anos de 2017 e 2019

\begin{tabular}{|c|c|c|c|}
\hline Ano & Homens trans & Mulheres trans/travestis & Total de solicitações \\
\hline $\mathbf{2 0 1 7}$ & $25(32 \%)$ & $53(68 \%)$ & 78 \\
\hline $\mathbf{2 0 1 8}$ & $34(35 \%)$ & $62(65 \%)$ & 96 \\
\hline $\mathbf{2 0 1 9}$ & $50(33 \%)$ & $101(67 \%)$ & 151 \\
\hline
\end{tabular}

Fonte: Santos (2019).

Segundo a Gerência de Políticas Educacionais em Educação Inclusiva, Direitos Humanos e Cidadania (GEIDH), a maioria dos/as estudantes que utilizam esta política é de mulheres transexuais/travestis, maiores de idade, matriculadas na EJAI, que residem na Região Metropolitana do Recife (RMR). Para Rosa, o nome social significa vida, inclusão. Quando a gente tem o nome social respeitado a gente tem tudo, o nome e a imagem se casam de uma forma maravilhosa! Ela utiliza o nome social desde a implementação da política no Estado, porém chama a atenção para a necessidade de formação docente nessa área: quando eu cheguei aqui na escola a preocupação era que não sabia como estava na chamada, mas na chamada está certinho: nome social e nome de batismo entre parênteses. Então, os professores já identificam. Eles identificam, mas eles não sabem a origem, não sabem quem somos nós, isso está errado. Claro que, com a convivência, com o dia a dia, estreitando laços, tem uma troca de carinho de ambas as partes. Mas eles não sabem o que é uma pessoa trans, eles não entendem. 
Os dados apresentados na Tabela 2 também nos desafiam a pensar sobre a crescente presença de homens trans ${ }^{9}$ na escola. Como ressaltado nos poucos estudos (ALMEIDA, 2012; ÁVILA; GROSSI, 2010; ÁVILA, 2014) sobre o tema no país, ainda há um número pequeno de pessoas que se autoidentificam assim no Brasil. Até 2010, a presença destes sujeitos em movimentos sociais LGBT era ínfima ou quase inexistente.

De acordo com Almeida (2012), não podemos pensar em homens trans como uma identidade homogênea, marcadores sociais de diferenças - como classe social, raça/cor, orientação sexual, geração, território - entram no jogo de produção de suas subjetividades. Porém a utilização do termo "transexual" ou "trans" como adjetivo é bastante comum entre eles, dando-lhes conforto psíquico, sentido de respeito e "alívio diante do encontro com uma unidade semântica capaz de oferecer inteligibilidade a suas trajetórias pessoais até então inomináveis e, por isso mesmo, mais abjetas" (ALMEIDA, 2012, p. 517).

O crescimento significativo do reconhecimento dessa identidade é algo relativamente recente e tem sido frequentemente relacionado à visibilidade de personagens televisivas, a trocas de informações em redes sociais, a encontros viabilizados em ambulatórios ligados ao "processo transexualizador" e à militância de personagens históricos.

Renato afirma que solicitou o uso do nome social ao conhecer a trajetória de homens trans através da televisão: Eu vi que era possível ser aquilo, tá ligado? Então, fui à escola e pedi para usar o nome que eu me sentia melhor. Disseram que eu não podia, mas imprimi a lei e mostrei na secretaria da escola. Num instante trocaram o meu nome e até hoje está lá. Para Fernando, João Nery ${ }^{10}$ foi essencial nesta etapa de sua vida: Eu procurei falar com ele em rede social, perguntei como era isso de usar o nome na escola. Depois que eu falei que morava em Pernambuco, ele me indicou Leonardo Tenório, que é um cara do movimento daqui, que enca-

\footnotetext{
9 Usamos o termo "homem trans" no sentido referenciado por Ávila e Grossi (2010), para se referir a sujeitos assignados biologicamente como mulheres que se identificam com o gênero masculino. Assim como Almeida (2012), consideramos equivalentes a esse termo as categorias "homem transexual", "transhomem", "transman", "female to male (FTM)" ou "transexual masculino".

${ }^{10}$ Psicólogo, escritor e ativista trans, João foi o primeiro homem transexual brasileiro a realizar cirurgia de redesignação sexual no Brasil, ainda em 1977. Escreveu "Erro de pessoa: Joana ou João?" e "Viagem solitária", livros que se tornaram referência entre a população trans no país. Faleceu em 2018, após diagnóstico e tratamento de câncer no pulmão.
} 
minhou meu caso para a Secretaria de Educação. Em pouco tempo, meu nome já estava no sistema. Os professores ficaram mais felizes do que eu quando viram que consegui mudar. Inclusive, alguns me ajudaram na hora de fazer o pedido.

A professora de Português que ensina Felipe na EJAI lhe acompanha desde a infância sendo peça fundamental em seu processo de transição e no uso do nome social: Eu disse a ela que antigamente era uma coisa e agora sou outra coisa. Ela nunca foi negativa, sempre apoiou e me orientou. As experiências vivenciadas por estes sujeitos representam as fragilidades e potencialidades dessa política educacional na rede pública de ensino em Pernambuco. Se, no primeiro caso, o espaço administrativo escolar demonstrou desconhecer a normativa, sendo o direito garantido em decorrência da insistência e do conhecimento legal do estudante, na segunda e terceira situação, o corpo docente passa a ter papel fundamental durante a requisição.

Outro aspecto importante de ressaltar é que, enquanto as pesquisas sobre travestis e mulheres trans (BENEDETTI, 2005; BENTO, 2011; CRUZ, 2011; FRANCO; CICILLINI, 2015) destacam o fenômeno da evasão como uma forte marca nas trajetórias escolares dessas pessoas, o mais comum entre os relatos de homens trans são as experiências de solidão, dificuldade de socialização na escola e busca de reconhecimento através do desempenho escolar (ÁVILA, 2014). Os dados de nosso estudo também nos dão algumas pistas nessa direção: enquanto as idades das estudantes trans/travestis entrevistadas variaram entre 19 e 42 anos, com média de 30 anos; as dos homens trans se concentraram na faixa etária dos 16 aos 22 anos, com média de 19 anos. As lembranças dos alunos, relatadas parcialmente na sessão anterior, ora remetem a situações de isolamento, dificuldade de socialização, tentativa de suicídio, ora dão ênfase ao protagonismo dentro da escola.

A Tabela 3 explicita a quantidade de estudantes, por faixa etária, que solicitaram o uso do nome social na escola. Percebe-se que a maioria tem mais de dezoito anos, no entanto, há um número crescente de pessoas em menoridade requisitando esse direito ao longo dos últimos três anos. Com relação ao predomínio da maioridade, este dado pode ser compreendido a partir da própria estrutura normativa: estudantes menores de dezoito anos precisam ter a autorização do pai, mãe ou responsável legal para utilização do nome social na unidade escolar, exigência que desconsidera as tensões e fragilidades dos laços familiares em relação à experiência transgênera. 
Tabela 3 - Número de estudantes, por faixa etária, que solicitaram o uso do nome social na rede estadual de ensino de Pernambuco

\begin{tabular}{|c|c|c|c|}
\hline Ano & Total de solicitações & Maiores de idade & Menores de idade \\
\hline $\mathbf{2 0 1 7}$ & 78 & $64(82 \%)$ & $14(18 \%)$ \\
\hline $\mathbf{2 0 1 8}$ & 96 & $68(71 \%)$ & $28(29 \%)$ \\
\hline $\mathbf{2 0 1 9}$ & 151 & $106(70 \%)$ & $45(30 \%)$ \\
\hline
\end{tabular}

Fonte: Santos (2019).

A tutela é ponto de discordância nos documentos que dispõem sobre nome social: a nota técnica emitida pela Comissão Especial de Diversidade Sexual do Conselho Federal da Ordem dos Advogados do Brasil (OAB), em 27 de setembro de 2017, e a Resolução n. 12 do Conselho Nacional de Combate à Discriminação e Promoção dos Direitos de Lésbicas, Gays, Bissexuais, Travestis e Transexuais (CNCD/LGBT) afirmam que a garantia do reconhecimento da identidade de gênero deve ser estendida a estudantes adolescentes, sem a necessidade de autorização. Já a resolução do Conselho Nacional de Educação reforça a prerrogativa do consentimento familiar como elemento indispensável no processo de solicitação.

A fim de que seja assegurado o respeito à identidade de gênero autopercebida pelas/os estudantes da rede básica de ensino, a Defensoria Pública de Pernambuco (DPPE) emitiu uma Recomendação Administrativa para a Secretaria de Educação do Estado. O documento orienta que, na hipótese de a/o estudante não contar com a autorização da família ou responsáveis legais para a solicitação do nome social, seja empregado o art. 142 do Estatuto da Criança e do Adolescente, orientando a/o estudante a buscar a Defensoria Pública do Estado, que promoverá a representação excepcional da/o interessada/o. Até o presente momento, foram registrados três casos como este, sendo dois em 2018 e um em 2019. Em todos eles, o direito ao nome social foi garantido.

Mesmo tendo a autorização da mãe para o uso do nome social, Heitor levou o caso até a Secretaria de Educação de Pernambuco. No ato da solicitação, a escola exigiu uma série de documentos que não fazem parte do procedimento e, ao ser notificada, alegou que não dispunha de funcionárias/os para alterar o nome no sistema eletrônico. Só a partir de uma visita técnica é que o direito do estudante foi garantido. Mas será que ter o nome social reconhecido é suficiente 
para ter sua identidade de gênero também reconhecida? A experiência do estudante responde cruelmente esta questão: Eu tinha que corrigir um trabalho de Geografia, os cadernos da galera. E aí, uma evangélica de lá da minha sala (eu vou chamar de evangélica porque não sei o nome dela) foi até o professor e falou assim: ela vai corrigir os cadernos e mais não sei o quê. Aí o professor falou: eu sei, ela vai corrigir os cadernos. Aí ela foi e repetiu de novo: ela vai. Aí eu fiquei olhando assim e eu fiquei meio que paralisado. Depois eu gritei: ele! É ele! Só que eles meio que pagaram de doido e não responderam.

Berenice Bento (2014) chama atenção para o fato instigante de que o Brasil é o único país que, apesar de não possuir uma legislação geral sobre os direitos fundamentais das pessoas trans, possui instituições que garantem o respeito à identidade de gênero através do reconhecimento do nome social. Para a autora, apesar de essa normatização garantir a diminuição dos constrangimentos nas esferas microssociais, ela funciona como uma espécie de "gambiarra legal", que não garante a ampliação de direitos, gera uma cidadania precária, caracterizada pela aprovação de conquistas a conta-gotas e que

[...] nos coloca diante de uma configuração discursiva que nos permite pensar a farsa do "diagnóstico" e da patologização de uma experiência humana tão diversa e plural como a dos gêneros. Se na universidade eu tenho o pleno direito a ser nomeada como eu me identifico, em outras instituições esse direito é condicionado à fala de um terceiro (um psiquiatra) que deverá atestar meu "transtorno" de identidade de gênero. É neste quadro confuso e quase surreal onde nos movemos quando discutimos o direito à identidade de gênero no Brasil. Como é possível um médico ou um juiz exigir um laudo médico quando na escola, no trabalho (em algumas repartições públicas), em alguns bancos, na universidade está garantido direito à autodeterminação de gênero? (BENTO, 2014, p. 177).

$\mathrm{Na}$ Tabela 4, sistematizamos o quantitativo de estudantes que solicitaram o uso do nome social na rede de ensino de acordo com a região do Estado. A interiorização desta política consiste num grande desafio. Conforme apontam os dados, a maioria das solicitações é proveniente da Região Metropolitana do Recife (RMR). 
Tabela 4 - Quantitativo de estudantes transgêneros que solicitaram o uso do nome social na rede de ensino de Pernambuco de acordo com a região do Estado

\begin{tabular}{|c|c|c|c|c|}
\hline Ano & RMR & Agreste & Zona da Mata & Sertão \\
\hline $\mathbf{2 0 1 7}$ & $44(56 \%)$ & $17(22 \%)$ & $8(10 \%)$ & $9(12 \%)$ \\
\hline $\mathbf{2 0 1 8}$ & $57(59 \%)$ & $16(17 \%)$ & $14(15 \%)$ & $9(9 \%)$ \\
\hline $\mathbf{2 0 1 9}$ & $98(65 \%)$ & $18(12 \%)$ & $18(12 \%)$ & $17(11 \%)$ \\
\hline
\end{tabular}

Fonte: Santos (2019).

Os relatos das/dos estudantes situados no interior de Pernambuco ressaltam a importância do envolvimento das/dos profissionais em educação na garantia desse direito. Celeste, estudante da Zona da Mata de Pernambuco, contou com o apoio do diretor da escola. Segundo a jovem, ele acredita que o número de estudantes usando nome social só não é maior no interior por conta dos colegas gestores que negam o direito dessas pessoas. É uma atitude de desrespeito que precisa ser combatida. Elizabeth também contou com a orientação da gestão e as diretrizes dadas foram essenciais para o seu regresso ao espaço escolar: eu sinto que agora as pessoas me respeitam mais, não tem isso de depender da boa vontade dos outros para me tratar da forma que eu mereço. Isso ajuda muito a gente! Davi afirma que, nos últimos dois anos, pôde ser quem realmente é: Fiquei muito feliz em colocar meu nome na prova como eu me reconheço. Fiquei muito feliz por estar na chamada. A placa também foi algo que eu achei legal. Se tiver outro trans por aqui, vai ver que aquele foi o primeiro trans que colocou o nome social na escola. Esse é o melhor momento na escola!

Assim que Fernando adotou o nome social, a gestão escolar passou nas salas explicando a situação. Um dos poucos casos de desrespeito à sua identidade de gênero veio de um estudante gay. A situação foi superada com a ajuda de um professor de Matemática que, em vários momentos, ouviu e aconselhou o estudante: Ele não era só um professor, ele virou meu amigo! Quando um sujeito escolhe seu nome social, está dizendo ao outro como quer ser identificado e reconhecido socialmente. Este dispositivo pode acionar outros, como o uso do banheiro na escola por estudantes trans. 
Tabela 5 - Quantitativo de estudantes transgêneros que solicitaram o uso do nome social matriculados na EJAl da rede estadual de Pernambuco

\begin{tabular}{|c|c|c|}
\hline Ano & $\begin{array}{c}\text { Solicitações na rede de ensino } \\
\text { de PE }\end{array}$ & Solicitações na EJAI \\
\hline $\mathbf{2 0 1 7}$ & 78 & $45(58 \%)$ \\
\hline $\mathbf{2 0 1 8}$ & 96 & $61(64 \%)$ \\
\hline $\mathbf{2 0 1 9}$ & 151 & $98(65 \%)$ \\
\hline
\end{tabular}

Fonte: Santos (2019).

A maioria das/os estudantes que solicitaram o uso do nome social está matriculada na EJAl. A Educação de Jovens e Adultos (EJA) resulta de lutas históricas no campo educacional desde meados do século passado (PAIVA, 2003), é uma modalidade da educação básica prevista na Lei de Diretrizes e Bases da Educação (LDB 9394/96) e no Plano Nacional de Educação 2014/2024 (HADDAD; DI PIERRO, 2000; DI PIERRO, 2005). Em Pernambuco, no intuito de garantir visibilidade à população idosa, resoluções em nível estadual e municipal alteraram a sua nomenclatura para Educação de Jovens, Adultos e Idosos (EJAI).

Destinada àquelas/es que não tiveram acesso ou continuidade de estudos no ensino fundamental e médio na idade própria, esta modalidade contempla especialmente dois perfis de estudantes: 1) adultos/as e/ou idosos/as, com baixa ou nenhuma escolaridade, que viveram numa época em que o acesso à educação era precário e/ou tiveram de trabalhar precocemente para garantir o sustento familiar; 2) jovens cuja trajetória tem sido marcada por intensos conflitos, seja na escola, seja fora dos seus muros, estimulando movimentos de "evasão" e reprovação. A preponderância de matrícula nessa modalidade entre os/as estudantes trans aponta para uma constatação importante no monitoramento da política: o retorno desses sujeitos aos espaços escolares após a expulsão indireta.

Essas trajetórias nos possibilitam pensar nos ambivalentes modos de existência que circulam e se cruzam no currículo, nos tortuosos e incompletos processos de criação de vidas forjados nas brechas da estrutura (cis)normativa e no efeito produtivo dos deslocamentos da política sexual no Brasil (CARRARA, 2015) das últimas duas décadas. 


\section{CONSIDERAÇÕES FINAIS}

Os resultados de pesquisa apresentados e discutidos ao longo do artigo, mesmo que de forma panorâmica e parcial, apontam indícios bastante consistentes de que as mudanças nas políticas públicas de educação e na cultura escolar, potencializadas pelo fortalecimento dos discursos de inclusão escolar e de garantia dos direitos das pessoas LGBT na vida social e especialmente no campo educacional, abriram caminho para que um contingente significativo e crescente de pessoas transgêneres que haviam sido informalmente expulsas de sua trajetória de escolarização voltassem a demandar o acesso à escola e a investir na perspectiva da educação escolar como caminho de realização subjetiva e de viabilização de outras possibilidades de acesso à cidadania formal e ao mundo do trabalho. A Educação de Jovens, Adultos e Idosos (EJAI) - como é denominada em Pernambuco - tornou-se a via privilegiada para o acesso e o reingresso das pessoas trans na rede pública de ensino.

Apesar do histórico comum de experiências traumáticas no contexto escolar, sobretudo entre as/os estudantes mais velhas/os, o desejo de retorno à escola é frequentemente alimentado pela disposição de lutar - individual e/ou coletivamente - pela construção da possibilidade de reconhecimento da dignidade social e de alcance de condições mais favoráveis de vida e trabalho que seriam virtualmente inacessíveis às pessoas travestis e transgêneres em gerações anteriores. A aprovação de leis e normatizações que reconhecem e buscam tornar efetiva a garantia do uso e do respeito ao nome social de pessoas trans na vida escolar tem tido um papel de destaque nesse processo de reinserção na escolarização. A inserção formal das temáticas e as mudanças na forma de abordagem das questões de gênero e sexualidade nas políticas curriculares e de formação docente também são aspectos que surgem nos resultados apresentados e merecem uma maior discussão em relação a seu papel nesse processo. Sobretudo, na investigação de suas relações com os deslocamentos que passam a ocorrer na própria cultura escolar.

Embora a luta das pessoas que não se conformam ao padrão cis-heteronormativo pelo reconhecimento de sua dignidade e direitos tenha alcançado conquistas importantes no campo da educação escolar brasileira ao longo das últimas décadas, como é possível observar, os dispositivos e mecanismos de normatização, controle, exclusão e eliminação social ainda são extremamente 
poderosos e impõem barreiras e resistências brutais aos que encarnam o questionamento e a transgressão desses padrões. A segregação de espaços públicos, como os banheiros escolares e os meios de transporte, as ameaças e práticas cotidianas de violência que permanecem naturalizadas na rotina das escolas e das cidades são a manifestação mais visível desses mecanismos. A ameaça mais aguda a esse caminho histórico de construção subjetiva, de luta e de conquista de direitos, entretanto, vem do crescente processo político de reafirmação das estruturas tradicionais de hierarquização, subjugação e exclusão social, o qual tem ganhado força através da articulação de "novos" discursos e movimentos conservadores em várias partes do mundo.

No contexto brasileiro, esse movimento tem se constituído, sobretudo, através da disseminação de um pânico moral em torno das questões de gênero e sexualidade, investindo, agressivamente, no reforço da abjeção contra as pessoas LGBT e, especialmente, contra as pessoas trans. O campo das políticas educacionais, escolares e curriculares foi eleito como um dos polos centrais de disputa para esses movimentos e, desse modo, mesmo as conquistas já consolidadas através de leis e políticas públicas encontram-se novamente sob ameaça. Diante desse cenário, o trabalho delineado neste artigo busca apresentar-se como um recurso consistente para demonstrar o sentido e o alcance real dos debates e políticas de gênero e sexualidade no âmbito da educação, assim como para desmistificar as tentativas de reforçar estereótipos e projetar inimigos ameaçadores para buscar justificar a (re)produção de projetos históricos de dominação e exploração através do medo, do ódio e da violência.

\section{REFERÊNCIAS}

ASSOCIAÇÃO BRASILEIRA DE LÉSBICAS, GAYS, BISSEXUAIS, TRAVESTIS E TRANSEXUAIS (AGBLT). Secretaria de Educação. Pesquisa nacional sobre o ambiente escolar no Brasil 2016: as experiências de adolescentes e jovens lésbicas, gays, bissexuais, travestis e transexuais em nossos ambientes educacionais. Curitiba: AGBLT, 2016.

ALMEIDA, G. 'Homens trans': novos matizes na aquarela das masculinidades? Estudos Feministas, Florianópolis, v. 20, n. 2, p. 513-23, maio/ago. 2012.

ASSOCIAÇÃO NACIONAL DE TRAVESTIS E TRANSEXUAIS (ANTRA). Mapa dos assassinatos de travestis e transexuais no Brasil em 2017. Brasil: Antra, 2018. Disponível em: https:// 
antrabrasil.files.wordpress.com/2018/02/relatc3b3rio-mapa-dos-assassinatos-2017antra.pdf. Acesso em 25 nov. 2019.

ÁVILA, S. Transmasculinidades: a emergência de novas identidades políticas e sociais. Rio de Janeiro: Multifoco, 2014.

ÁVILA, S.; GROSSI, M. P. Maria, Maria João, João: reflexões sobre a transexperiência masculina. In: FAZENDO GÊNERO: DIÁSPORAS, DIVERSIDADE, DESLOCAMENTOS, 9., 2010, Florianópolis, SC. Anais [...]. Florianópolis: UFSC, 2010.

BENEDETTI, M. Toda feita: o corpo e o gênero das travestis. Rio de Janeiro: Garamond, 2005.

BENEVIDES, B.; NOGUEIRA, S. N. B. Dossiê: Assassinatos e violência contra travestis e transexuais no Brasil em 2018. Brasil: ANTRA/IBTE, 2019. Disponível em: https:// antrabrasil.files.wordpress.com/2019/01/dossie-dos-assassinatos-e-violencia-contrapessoas-trans-em-2018.pdf. Acesso em: 25 nov. 2019.

BENTO, B. Nome social para pessoas trans: cidadania precária e gambiarra legal. Contemporânea, São Carlos, SP, v. 4, n. 1 p. 165-82, jan./jun. 2014.

BENTO, B. Na escola se aprende que a diferença faz a diferença. Revista Estudos Feministas, Florianópolis, v. 19, n. 2, p. 549-59, maio/ago. 2011.

BROWNE, K. Genderism and the Bathroom Problem: (re)materialising sexed sites, (re) creating sexed bodies. Gender, Place \& Culture, Londres, v. 11, n. 3. p. 331-46, 2004.

BUTLER, J. Quadros de guerra: quando a vida é passível de luto? Rio de Janeiro: Civilização Brasileira, 2018.

BUTLER, J. Corpos que pesam: sobre os limites discursivos do 'sexo'. In: LOURO, G. L. (Org.). O corpo educado: pedagogias da sexualidade. Belo Horizonte: Autêntica, 2000.

CARRARA, S. Moralidades, racionalidades e políticas sexuais no Brasil contemporâneo. Mana, Rio de Janeiro, v. 21, n. 2, p. 323-45, maio/ago. 2015.

CRUZ, E. F. Banheiros, travestis, relações de gênero e diferenças no cotidiano da escola. Psicologia Política, São Paulo, v. 11, n. 21, p. 73-90, jan./jun. 2011.

DI PIERRO, M. C. Notas sobre a redefinição da identidade e das políticas públicas de Educação de Jovens e Adultos no Brasil. Educação \& Sociedade, Campinas, SP, v. 26, n. 92, especial, p. 1115-39, out. 2005. 
Trajetórias transgêneras na educação de jovens, adultos e idosos: conquistas, horizontes e ameaças entre tempos, espaços e sujeitos escolares

FRANCO, N.; CICILLINI, G. A. Professoras trans brasileiras em seu processo de escolarização. Revista Estudos Feministas, Florianópolis, v. 23, n. 2, p. 325-46, maio/ago. 2015.

HADDAD, S.; DI PIERRO, M. C. Escolarização de jovens e adultos. Revista Brasileira de Educação, Rio de janeiro, n. 14, p. 108-94, maio/ago. 2000.

HALBERSTAM, J. Female masculinity. Durham, NC: Duke University Press, 1998.

HALL, S. A identidade cultural na pós-modernidade. Rio de Janeiro: DP \& A, 2003.

HANNA, W.; CUNHA, T. Discriminação rouba de transexuais o direito ao estudo. Correio Brasiliense. [s.d.]. Disponível em: http://especiais.correiobraziliense.com.br/violenciae-discriminacao-roubam-de-transexuais-o-direito-ao-estudo. Acesso em: 10 set. 2019.

HISSA, C. V.; NOGUEIRA, M. L. M. Cidade-corpo. Revista UFMG, Belo Horizonte, v. 20, n. 1, p. 54-77, jan./jun. 2013.

JESUS, J. G. Orientações sobre identidade de gênero: conceitos e termos. Brasília, 2012. Disponível em: http://www.diversidadesexual.com.br/wp-content/uploads/2013/04/ G\%C3\%8ANERO-CONCEITOS-E-TERMOS.pdf. Acesso em: 25 nov. 2019.

JOVCHELOVITCH, S,; BAUER, M. Entrevista narrativa. In: BAUER, M.; GASKELL, G. (Org.). Pesquisa qualitativa com texto, imagem e som: um manual prático. Petrópolis, RJ: Vozes, 2010. p. 90-113.

JUNQUEIRA, R. D. Homofobia nas escolas: um problema de todos. In: JUNQUEIRA, R. D. (Org.). Diversidade sexual na escola: problematizações sobre a homofobia nas escolas. Brasília: Ministério da Educação, Secretaria de Educação Continuada, Alfabetização e Diversidade, UNESCO, 2009.

LACLAU, E.; MOUFFE, C. Hegemonia e estratégia socialista: por uma política democrática radical. São Paulo: Intermeios; Brasília: CNPq, 2015.

LANZ, L. Ser uma pessoa transgênera é ser um não-ser. Periódicus, Salvador, n. 5, v. 1, p. 205-20, maio/out. 2016.

LEITE JÚNOR, J. "Nossos corpos também mudam": sexo, gênero e a invenção das categorias "travesti" e "transexual" no discurso científico. 233fs. Tese (Doutorado em Ciências Sociais) - Pontifícia Universidade Católica de São Paulo, São Paulo, 2008.

MISKOLCI, R. Pânicos morais e controle social: reflexões sobre o casamento gay. Cadernos Pagu, Campinas, SP, n. 28, p. 101-28, jan./jun. 2007. 
MUNT, S. Butch/femme: inside lesbian gender. London: Cassel, 1998.

NERI, M. C. O tempo de permanência na escola e os sem-escola. Rio de Janeiro: FGV/ IBRE/CPS, 2009.

OLIVEIRA, A. L. A. R. M.; OLIVEIRA, G. G. S. Curriculum policies of gender and sexuality in Brazil. Transnational Curriculum Inquiry, v. 16, n. 1, p. 38-60, 2019.

OLIVEIRA, A. L. A. R. M; OLIVEIRA, G. G. S. Novas tentativas de controle moral da educação: conflitos sobre gênero e sexualidade no currículo e na formação docente. Educação Unisinos, São Leopoldo, RS, v. 22, n. 1, p. 16-25, jan./mar. 2018.

PAIVA, V. História da educação popular no Brasil. São Paulo: Edições Loyola, 2003.

PARKER, R.; CAMARGO JÚNIOR, K. R. Pobreza e HIV/AIDS: aspectos antropológicos e sociológicos. Cadernos de Saúde Pública, Rio de Janeiro, v. 16 (Sup. 1), p. 89-102, 2000.

PELÚCIO, L. "Sin papeles" pero con glamur: Migración de travestis brasileñas a España (Reflexiones iniciales). Vibrant, Florianópolis, v. 6, n. 1, p. 170-97, jan./jun. 2009.

PRÓCHNO, C. C. S. C.; ROCHA, R. M. G. O jogo do nome nas subjetividades travestis. Psicologia \& Sociedade, Belo Horizonte, v. 23, n. 2, p. 254-61, maio/ago. 2011.

RANNIERY, T. Corpos feitos de plástico, pó e glitter: currículos para dicções heterogêneas e visibilidades improváveis. 412F. Tese (Doutorado em Educação) - Universidade do Estado do Rio de Janeiro, 2016.

RASMUSSEN, M. L. Beyond gender identity? Gender and Education, London, v. 21, n. 4, p. 431-47, 2009.

RUBIN, G. Thinking sex: notes for a radical theory of the politics of sexuality. In: ABELOVE, H.; BARALE, M.; HALPERIN, D. (Org.). The lesbian and gay studies reader. Nova York: Routledge, 1993.

SANTOS, D. "Sobrevivi para contar": experiências escolares transgêneras na educação de jovens, adultos e idosos (EJAI). 147f. Dissertação (Mestrado em Educação) - Universidade Federal de Pernambuco, Recife, 2019. 


\section{Sobre os autores:}

Dayvi Santos: Mestre em Educação pela Universidade Federal de Pernambuco (UFPE), coordenadora da Unidade de Educação para as relações de gênero e sexualidade da Secretaria de Educação de Pernambuco. E-mail: dayvi.santos@gmail.com, Orcid: http://orcid.org/0000-0002-2035-9526

Anna Luiza Araújo Ramos Martins: Doutora em Educação, mestre e graduada em Psicologia pela Universidade Federal de Pernambuco (UFPE). Professora do Programa de Pós-Graduação em Educação da UFPE. E-mail: alarmo@uol.com.br, Orcid: http://orcid.org/0000-0002-0620-3322

Recebido em 12 de agosto de 2019 Aprovado em 11 de novembro 2019 
